\title{
El memorial de las identidades: \\ entre héroes y villanos. En la busca de sí y de los demás también ${ }^{1}$
}

\author{
Identities' Memorial: \\ Between Peasants and Heroes. In Search of Oneself and Others
}

Martha Cecilia Herrera*

A Margarita Garrido, quien con su mirada me hizo reafirmar en las reflexiones que hago en este memorial

\section{Resumen}

En este artículo se hace una presentación general de los resultados investigativos que, sobre la historia de Colombia en el siglo XX y sobre los textos escolares de ciencias sociales como bases fundamentales de la construcción de la identidad nacional, ha dado a la luz el Grupo de Investigación en Educación y Cultura Política de la Universidad Pedagógica Nacional. De la misma manera, se ofrece una visión panorámica de cómo los ciudadanos colombianos del siglo XX construyeron su imaginario histórico y político a partir de los manuales escolares de historia, geografía y civismo con que los educaron, para dibujar claramente una determinada identidad nacional, en contraste con la situación de los colombianos actuales basan su imaginario nacional en la cultura mediática.

\section{Palabras claves:}

Manuales escolares, identidad, historia, geografía, civismo, héroe, territorio, nación.

\section{Abstract}

This article deals with a general presentation of the results which the research team called Investigación en Educación y Cultura Política de la Universidad Pedagógica Nacional have released about the Colombian History during the $20^{\text {th }}$ century, and about the Social Sciences textbooks as basements of the national identity construction. In the same way, the current text gives a panoramic review about how the $20^{\text {th }}$ century Colombian citizens built their politic and historical imaginary, based on the information they got from the History, Geography and Civics textbooks, which they were taught with, in order to define a clear and specific national identity, in contrast to the situation of nowadays Colombians, who draw their national imaginary from the mass media culture.

Keywords:

School handbooks, identity, History, Geography, civism, hero, territory, nation.

Artículo recibido el 15 de febrero de 2007 y aprobado el 30 de abril de 2007

* Doctora en filosofía e historia de la educación, profesora investigadora de la Universidad Pedagógica Nacional. Miembro del Grupo de Investigación Educación y Cultura Política.

1 Artículo preparado para la sustentación del trabajo "La identidad nacional en los textos de ciencias sociales: Colombia 1900-1950", como requisito para aspirar a la categoría de profesora titular. Bogotá, 15 de noviembre de 2006. 


\section{Asuntos que obsesionan: la invención del país moderno}

Mis preocupaciones como ser humano han girado, en gran medida, en torno a asuntos de carácter histórico, siempre en la búsqueda incesante de identidad, de preguntas acuciantes sobre quién soy. Así, interpelada por estos interrogantes, al saberme atada a lazos familiares y sociales, parto en busca de memorias e historias colectivas que me den claves sobre asuntos que irán marcando los derroteros de mi trayectoria como investigadora. Estos asuntos, a su vez, se han multiplicado con el transcurrir de los años, como si fuesen piedras arrojadas en el turbulento mar del conocimiento y cuyas ondas se reprodujeran de manera infinita, dando pie a nuevos círculos de interrogantes.

Cuando era niña me gustaba la historia universal, la cual aprendía de memoria con placer y cuyos mundos ajenos y extranjeros me llenaban de pasión. Cuando era joven y estudié sociología, busqué las causas del aborto en la discriminación social de la mujer y me adentré hasta los orígenes de los sistemas patriarcales, sin que lograra respuestas para muchas de mis preguntas, mostrándome más bien las complejidades de las divisiones sociales y culturales, no sólo de género sino de etnia, clase, edad, religión, entre otras.

Sin embargo, varias de estas preguntas se han dirigido en forma reiterada a las primeras décadas del siglo XX, como si estuvieran atadas a la memoria colectiva de las dos generaciones que me antecedieron -mis padres y mis abuelos-, al igual que los ritmos de las transformaciones del campo a la ciudad; luces y sombras en el calidoscopio de las memorias que dan cuenta de la invención del país moderno. Es así como las preocupaciones por Colombia y el siglo XX me impactaron fuertemente, a partir de mi trayectoria política y de mi maestría en historia en la Universidad Nacional, y el doctorado en filosofía e historia de la educación en la Unicamp en Brasil.

Una mujer del siglo XX, eso soy, no cabe duda. ¡Pero la vida es tan corta, la investigación es tan ardua y apenas he alcanzado a saber tan pocas cosas! Me muevo lentamente de preocupaciones macroestructurales, apoyadas en mi formación de socióloga, con la influencia de enfoques funcionalistas y del materialismo histórico, hacia problemas de la vida cotidiana, de matrices culturales, de los gestos y los ritos que marcan nuestros comportamientos, nuestros sentimientos, nuestras luchas y utopías, nuestras acciones colectivas. En busca de mí misma y, en ella, en la busca de lo que no soy, de lo que hemos sido y no seremos, encuentro, entonces, en la nueva historia y, más recientemente, en las tradiciones hermenéuticas, algunas luces para integrar estas problemáticas a mis objetos de estudio. Marcas profundas labradas en mi cuerpo a partir de la conciencia de que soy un ser histórico, una mujer que nació a mediados del siglo XX y lleva en su ser parte de las memorias de todo el siglo, parte de lo que a sus abuelos, a sus padres, a ella y a sus contemporáneos les tocó vivir. Son las señales insondables de la experiencia que galopan sobre nuestros destinos y dotan de sentido nuestras prácticas sociales e investigativas.

Aquí estoy, entonces, ante ustedes, señores del jurado, sometida nuevamente a la inquietante docilidad de que mis esfuerzos sean evaluados y sometidos a calificación; aquí estoy frente a una mesa de extranjeros de mí misma. Las huellas marcantes de la escolaridad, de las instituciones y de los rituales del mundo académico, puestas en acción una vez más. No obstante, a lo largo de esta primera mitad del siglo de mi vida, algo ha cambiado en mí definitivamente, unido a la convicción de que el investigador y las prácticas que éste lleva a cabo deben someterse a socioanálisis permanente, para sondear las motivaciones personales y colectivas que subyacen a la búsqueda de conocimiento, para mostrar las limitaciones, la certeza de los hallazgos parciales, los desconciertos, las intuiciones, lo que hay de individual, de subjetivo en nuestras búsquedas. Es esto lo que me permite no inquietarme tanto al sentirme desnuda frente al jurado, que me mira desde el más allá...

Así entonces, desde mi desnudez, trato de mostrar las huellas que han trazado esos senderos, senderos en los que he deambulado y pasado internada varias décadas de mi vida. De este modo, puedo decir que la investigación que hoy presento 
ante ustedes constituye un nudo dentro de una red de sondeos sobre Colombia en la primera mitad del siglo XX, de acercamientos sucesivos a aspectos relacionados con la educación, la cultura, la política y algunos de sus desdoblamientos. En ella se muestra buena parte de los asuntos que me han interesado, obsesionado como investigadora, los cuales me sitúan como un ser social atento a su historia y a la de sus antepasados; como un ser en busca de un presente menos sombrío y un futuro más promisorio. Vana y fuerte ilusión que me posibilita el puente entre pasado, presente y futuro, en el marco de las tensiones dadas entre lo que Kosselleck ha llamado el espacio de la experiencia y el horizonte de expectativas'1.

Es así como las diferentes investigaciones que he llevado a cabo sobre la Colombia del siglo XX y mis vivencias personales, a mis 50 años de existencia, se entretejen de manera abigarrada y me permiten hacer este escrito en el que presento algunas ideas sobre la investigación en torno a manuales escolares e identidad nacional, llevada a cabo con la cofinanciación de Colciencias en el año de 2002 y de la cual fui investigadora principal. En este trabajo participaron como coinvestigadores Alexis Pinilla y Luz Marina Suaza, miembros del Grupo de Investigación en Educación y Cultura Política, que fundé en el año de 1998 en la Universidad Pedagógica Nacional. Esta investigación, publicada como libro en 20032, muestra búsquedas no sólo relacionadas conmigo, sino también con quienes me han acompañado, de modo decidido, en el reto de crear un grupo y tejer sueños colectivos.

Tejeré entonces mi reflexión sobre los resultados del análisis de los textos escolares de ciencias sociales, publicados entre 1900 y 1950, trayendo a veces las voces de testigos del siglo $\mathrm{XX}$, algunos muertos, otros vivos, unos mis allegados, otros más distantes, pero a su vez presentes, para sentir que no estoy sola en ese viaje hacia el pasado. Lo anterior

1 Reinhart Kosselleck (1993). Futuro pasado: para una semántica de los tiempos históricos. Barcelona: Paidós, pp. 333-357.

2 Martha Cecilia Herrera, Alexis V. Pinilla Díaz y Luz Marina Suaza (2003). La identidad nacional en los textos escolares de ciencias sociales: Colombia, 1900-1950. Bogotá: Ántropos. es un intento de evocar ambientes que recreen la época en la que se escribieron estos manuales, pero también se enseñaron y aprendieron, conjugándose, a la par con los esfuerzos de editores y libreros; una red de sujetos ligados, de una $\mathrm{u}$ otra manera con la intencionalidad de educar o ser educados, de modelar el país moderno y los ciudadanos que para este se requerían: maestros, alumnos, padres de familia, individuos corrientes, entre muchos otros. Pero también una red de la que forman parte el investigador y sus propios fantasmas.

\section{Habitando el siglo $X X$}

¿Cómo se constituye un orden social? ¿Cuáles son los hilos sutiles que van estructurando nuestras maneras de ser y de estar en el mundo? Memorias abigarradas en las que se superponen trayectorias biográficas donde lo individual y lo social se desdibuja entremezclándose. Memorias colectivas e individuales que construyen identidades y alteridades cambiantes y ambiguas; configuraciones elusivas que componen la trama de nuestra existencia y de las relaciones sociales que nos entretejen.

¿Y qué papel desempeñan en este entramado los manuales escolares? ¿Cuáles son las huellas que dejan, o por lo menos que pretenden dejar? Imágenes de cómo una sociedad se representa a sí misma y pretende darse continuidad a través de interpelaciones que buscan identidad y sentido de pertenencia colectiva... Mi mamá, que está de visita, acaricia con placer los manuales que he traído de la Biblioteca Luis Ángel Arango. Ella sólo estudió parte de la primaria pero le apasionaba la historia y, eso sí, no descansó hasta ver a sus seis hijos educados y profesionales. "No quería que fueran tan pobres como yo fui, que pasaran tantos trabajos", alcanza a decirme. Contempla uno de los libros y al ver el escudo nacional, el gorro frigio y evocar a Panamá, recita lo que le enseñaron: "Panamá, donde moran los traidores, donde reina la falsía”. Memoria social escolar poderosa, 88 años y todavía conserva estas imágenes y sus interpelaciones; frases cortas pero contundentes, que desencadenan diversas emociones en su cuerpo; las observo en su rostro lleno de infinitas arrugas, en sus ojos que brillan con lo que 
considera las certezas. "Nos traicionaron cuando nos quitaron Panamá”, continúa. ¿Cuánto de todo esto hemos aprendido a través de los manuales escolares?

Mis padres habitaron el siglo XX, cuando las ciudades colombianas todavía se confundían con el campo, cuando la pobreza dolía pero no tanto como ahora, porque por lo menos se podían, sembrar coles en el solar y comer con sal cuando los tiempos arreciaban, como me cuenta mi madre, ya casi una nonagenaria. Nacida en 1918, llega a la ciudad en su adolescencia y me habla del revés sufrido por su familia con el ascenso de los liberales al poder en los años treinta, lo cual llevó a vivencias personales que marcaron su socialización política: "Yo odié a los liberales a muerte porque cuando subieron al poder despidieron a mi papá del ferrocarril y aguantamos mucha hambre", me dice con emoción todavía contenida en su garganta. Y siento que nuestras percepciones del mundo están marcadas por las experiencias vividas en parte por lo deliberado, pero en muy buena parte, también por los asuntos colaterales, por las miradas oblicuas. Una multiplicidad de fluidos que se mezclan, yuxtaponen e incorporan con fuerza, dando forma a nuestras representaciones del mundo y los mapas que nos ayudan a orientarnos dentro de él, a nuestras emociones, a nuestros deseos...

Introduzcámonos entonces, tal vez con el asombro con que lo podría haber hecho alguno de mis padres, o tal vez de los de ustedes, a las ciudades latinoamericanas de principios del siglo y a los héroes que en ella se erigían, a los monumentos como lugares de la memoria ${ }^{3}$, a veces equívocos, recreados en buena parte por los textos escolares; adentrémonos, en los olores entremezclados del campo y de la urbe, en la nostalgia que sentía la pérdida de la comunión entre individuo y naturaleza, a través de la mano de un poeta brasileño, Manoel de Barros, con su poema "Sobre cachivaches", acariciando, al mismo tiempo, el pájaro que diseñó su hija para

3 Pierre Nora (dir.) (2001). Les lieux de mémoire, coll «Quarto». París, Gallimard. ilustrar este poema, y revelando, una vez más, los lazos generacionales de la memoria:

\section{"Sobre cachivaches"}

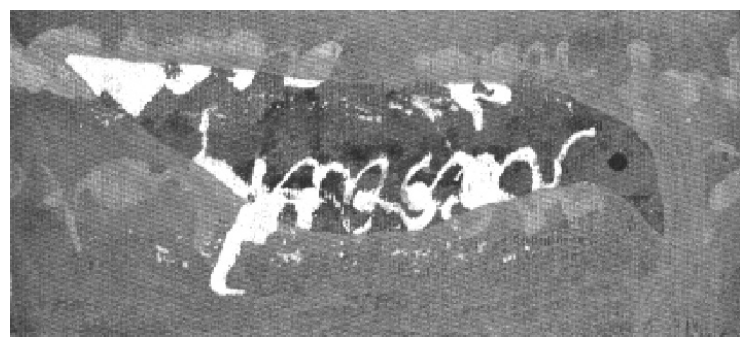

Passarinho (dibujo de Martha Barros).

Tal vez porque fui criado en un lugar donde no había juguetes fabricados y teníamos que hacer nuestros propios juguetes. Éstos eran bueyecitos de hueso, bolas hechas de medias de seda, automóviles de lata. También hacía de cuenta que el sapo era un buey de establo y yo viajaba de sapo. Jugaba a oír en las conchas los orígenes del mundo. Por esto extrañé mucho ese lugar cuando más tarde necesité vivir en la ciudad. En la ciudad, un día le conté a mi madre que había visto en la plaza un hombre montado en un caballo de piedra, que mostraba un cuchillo largo hacia lo alto. Mi mamá me corrigió que no era un cuchillo sino una espada. Y que el hombre era un héroe de nuestra historia. Claro que yo no tenía educación de ciudad para saber que héroe era un hombre sentado en un caballo de piedra. Ellos eran personas de la historia que algún día defendieron nuestra patria. Para mí, aquellos hombres encima de la piedra eran basura, cachivaches viejos. Serían cachivaches de la historia. Porque yo creía que una vez en el viento esos hombres serían como trastes, como cualquier pedazo de camisa al viento. Yo me acordaba de los espantapájaros vestidos con mis camisas. El mundo era un lugar complicado para un niño que venía del campo. No vi ninguna cosa más bonita en la ciudad que un pajarito. Vi que todo lo que el hombre fabrica se vuelve cachivache: bicicleta, avión, automóvil. Sólo lo que no se vuelve cachivache es ave, árbol, rana, piedra. Hasta la nave espacial se vuelve cachivache. Ahora yo pienso en una garza blanca del riachuelo como 
más bonita que una nave espacial. Pido disculpas por cometer esta verdad 4 .

Por mi parte, a mí los héroes, con sus grandes patillas, siempre me parecieron habitantes exclusivos del mundo de los manuales; todos tenían un sabor a historia sagrada que interesaba por su lenguaje cifrado, por las imágenes de los grabados que las fijaban con la intensidad que sólo podían darles miles y miles de rayitas trazadas con perfecta simetría. De los manuales de historia no me acuerdo mucho, pero de la historia sagrada sí; todavía me parece estarla acariciando desde su misma portada, ver aún sus imágenes: la zarza ardiente o los soles y rayos de donde emergía el Todopoderoso, o las escaleras con las que soñó Jacob, imagen de la conexión entre lo divino y lo terreno en nuestra indefensión como seres humanos que cometimos el pecado original de la existencia.

\section{El país visto en los ojos de los manuales}

¿Qué mostraban los manuales que se publicaron y se leían en la primera mitad del siglo XX? ¿Qué huellas dejaron ver de lo que nos ha constituido como nación, como pueblo, como nosotros mismos? Entendemos los manuales escolares como mediaciones culturales, como productos complejos situados "en la frontera de la cultura, la pedagogía, la producción editorial y la sociedad". Y, en este sentido, una de las precauciones que deberíamos tener es saber que:

Los autores de los libros didácticos no son simples espectadores de su tiempo, ellos reivindican un status, el de agente. El libro didáctico no es un simple espejo, él modifica la realidad para educar a las nuevas generaciones dando una imagen deformada, esquematizada y moldeada, frecuentemente de forma favorable, en donde las acciones contrarias a la moral son casi siempre castigadas ejemplarmente y los conflictos sociales, los actos delictivos o la violencia cotidiana son sistemáticamente silenciados, los historiadores se interesan justamente por el análisis de esa

4 Manoel Barros, Sobre sucatas, poema XV, en Memórias inventadas: a infancia. São Paulo: Planeta. ruptura entre ficción y realidad, es decir por las intenciones de los autores ${ }^{5}$.

¿Qué querían nuestros autores? ¿Qué imágenes construían sobre el país, las regiones que lo componían, los individuos que lo poblaban, los patrones culturales que lo regían? Memorias e historias personales nutridas de historias colectivas... ¿qué de todas estas narraciones han marcado nuestras culturas políticas? Veamos:

En la primera mitad del siglo XX, las políticas educativas en torno a saberes relacionados con las ciencias sociales, estuvieron ligadas a la promoción del imaginario que las élites tenían sobre el Estado nación, en donde la identidad nacional se articuló a la construcción de un proyecto político que dejó de lado la diversidad cultural y regional, así como la pluralidad de las expresiones políticas existentes, en donde lo nacional se entendió marcado por lo estatal. Aspectos que si bien podemos decir hacen parte de la lógica que caracterizó este periodo histórico, marcó de manera peculiar nuestros modos de ser como sujetos individuales y colectivos, así como nuestros imaginarios sobre lo social, lo cual es lo que nos interesa evidenciar.

La intención de los manuales era promover el ideario de la unidad nacional a partir de referentes como el territorio, entendido como el espacio en el que cobra vida la nación; la ley, como fuente de orden y gobernabilidad de los sistemas republicanos; la religión católica, como modeladora del alma nacional; la lengua castellana, como vaso comunicante entre la población, y la iconografía patriótica, como fuente de los arquetipos que hay que imitar. Estos elementos que entraron a formar parte de los imaginarios sociales y las expresiones simbólicas en torno a la consolidación del Estadonación y a los referentes identitarios de allí derivados.

En general, los fines de la historia, la geografía y la cívica apuntaron hacia la formación de ciudadanías virtuosas a través de la interiorización e incorporación, por parte de los sujetos escolares,

5 Alain Choppin (2002). História dos livros e das edições didáticas: sobre o estado da arte, en Paedagogica Histórica, Vol. 38, No. 1, 2002, pp.21-49. 
de lo que se estimaba el orden social legítimo6. En esta perspectiva, entre las principales funciones sociales asignadas a la historia están consolidar la nacionalidad colombiana, avivar el espíritu patriótico, moldear ideales de ciudadano con base en los héroes, en los sacrificios y en la sangre por ellos derramada para lograr nuestra independencia y alcanzar nuestra autonomía como república. Así, en uno de los textos se dice:

La patria es el patrimonio material y moral que nos legaron nuestros antepasados y que debemos transmitir a nuestros descendientes. No es solamente el suelo, es el alma nacional; es nuestra literatura y nuestras artes, el conjunto de ideas y de sentimientos que en el espíritu evoca el nombre de Colombia, y por sobre todo, es Bolívar, Santander, Ricaurte, y todos aquellos héroes que, al precio de su sangre, nos legaron la independencia y la libertad7.

La instrucción cívica se consideró un vehículo para formar tanto buenos cristianos como buenos ciudadanos, mediante la promoción de las normas y deberes para vivir en sociedad, la difusión sobre los modos de funcionamiento de las instituciones políticas, así como las tradiciones a las cuales había que acogerse, entre estas la herencia proveniente de los españoles, casi siempre apreciada como a la que había que adscribirse. Sobre este punto, en uno de los textos de enseñanza cívica, aparece lo siguiente referente a los españoles:

Nos legaron el idioma castellano, cuya claridad, riqueza y armonía no son superadas por lenguaje alguno de la tierra; nos trajeron y enseñaron las primeras nociones de las artes y las ciencias, y los rudimentos esenciales de los progresos humanos;

6 Estos saberes se unificaron en el concepto de enseñanzas sociales en 1933, en el programa de ensayo para escuelas primarias, donde se afirmaba que “La geografía, la historia y la instrucción cívica, al considerar al hombre como ciudadano, forman parte de la escuela elemental, como enseñanzas sociales primordiales". Inspección Nacional de Educación. Programas de ensayo para las escuelas primarias. Bogotá:Imprenta Nacional, 1933, p. 50. Posteriormente, en el año de 1939 se introdujeron como ciencias sociales, en los planes de estudio para las escuelas normales, a través del decreto 71.

7 Camilo Jiménez y Belisario Matos (1947). Resumen de la historia de Colombia. Texto para la enseñanza primaria. Bogotá: Librería Colombiana, p. 130. de ellos heredamos la marcada inclinación de nuestra raza a la espiritualidad, a las ciencias, a las artes y a todo orden de adelantos8.

Por su parte, la geografía se ligó al conocimiento del territorio nacional, lo cual era un principio básico para la formación del patriotismo, para la integración de comunidades imaginadas9. En un texto de geografía, publicado en 1914, se mostraban las virtudes de la enseñanza de la geografía, apoyada en el método inductivo:

En efecto, ¿qué persona que haya hecho el estudio de geografía por el método inductivo no será capaz de aquilatar más el amor por aquella parte del globo que lo vio nacer y lo sustenta con las producciones naturales de su suelo? ¿Quién con el sentimiento patrio adquirido de este modo no expone, con gusto, su vida para defenderla como a verdadera madre? ¿Quién que sepa apreciar el verdadero amor de patria no utiliza todos sus conocimientos para aprovechar las riquezas que, acaso, permanecen escondidas en el suelo que diariamente huella?10.

Las imágenes difundidas por los textos de geografía llenaban de prejuicios nuestras visiones sobre las regiones y las poblaciones que allí habitaban. De este modo, las imágenes más valorizadas las ocupaban los residentes de la zona andina $y$, principalmente, las élites bogotanas: "El sabanero reinoso. Puede clasificarse como el más apto para los destinos intelectuales. El medio en que vive, el clima que lo rodea y las comodidades de que disfruta en las ciudades... hacen de él un individuo culto y sociable"11. Por lo general, los modelos urbanos de las incipientes ciudades se situaban como paradigmas respecto a los modos de ser, a las costumbres y manejo del lenguaje, entre otras: "En toda la Re-

8 Ignacio Sánchez Santamaría, (1926). Cartilla cívica: catecismo del ciudadano para el uso de escuelas y colegios de Colombia. Bogotá: Sociedad Editorial, p. 4.

9 Benedict Anderson (1983). Imagined communities: reflections on the origins and spread of nationalism. Londres.

10 José Santos Montañés (1914). Curso de geografía elemental por el moderno sistema cíclico inductivo: primer ciclo escrito. Bogotá: Arboleda y Valencia, p. 6.

11 José Manuel Botero M., (1942). Geografía física y de la república de Colombia. Medellín: Tipografía Bedout. 
pública de Colombia se habla el castellano, aunque con mayor pureza y elegancia en las principales ciudades del país"12.

No hay que olvidar que algunos de los prejuicios y conceptos que se tenían sobre regiones distintas del centro del país se veían también movidos por pugnas entre las élites regionales, respecto al dominio del país y a los modelos y paradigmas que se debían difundir. Así, en el caso de la región de la costa atlántica, las aseveraciones que se hacen sobre los departamentos de Bolívar, Atlántico, Magdalena y La Guajira, son del siguiente orden: "Los costeños tienen temperamento expresivo, causa por la cual hablan y ríen mucho... carecen de espíritu público. Son muy sociables porque se rozan con gentes de otras naciones. El trabajo material entre ellos es escaso, y en religión como en ideales superiores, se muestran indiferentes"13.

Otra fuente de jerarquización la constituyó el asunto del género, en el cual la continua invisibilización de la mujer justificaba los lugares que se le asignaban en comparación con los hombres. Así, cuando se hablaba de la conveniencia de la instrucción cívica, al referirse a las mujeres se enfatizaba en que éstas carecían de derechos políticos, instándola, no obstante, a cumplir un papel de socialización política, de legitimación del orden establecido, debido a las funciones que se le asignaban como género: "En su carácter de hija, de hermana, de esposa, de madre de familia", la mujer debe "ejercer influencia sobre los hombres que pertenecen a su familia y aun sobre sus amigos"14.

Los niños se encontraban en una especie de sometimiento frente a los adultos, entendidos estos últimos como los representantes del orden social y encargados de dominar la naturaleza instintiva y díscola que acechaba en los espíritus y en los cuerpos infantiles:

12 E. Duarte Suárez (1942). Instrucción cívica para la enseñanza primaria. Bogotá: Editorial Iqueima, p. 65.

13 Juvenal Ríos (1943). Curso de antropogeografía colombiana, Bogotá: Tipografía Colón, p. 78.

14 Eduardo Posada y Roberto Cortázar Toledo (1912). Instrucción cívica. Bogotá, Editorial Casis, p. 1.
La vida escolar o los variados incidentes promovidos por la turbulencia infantil ofrecen numerosas coyunturas para que el maestro familiarizado con la psicología pedagógica vaya sembrando poco a poco, en el corazón del niño, los gérmenes de cuantas virtudes cívicas han de fructificar con el tiempo en el corazón del hombre, al par que sofoque desde sus primeros brotes las siniestras inclinaciones de que derivan los vicios sociales 15 .

Respecto a las imágenes del ciudadano, se tomó como referente a la aristocracia europea y se pensó en un ciudadano blanco y culto. Se propuso la consolidación de un modelo ciudadano basado en el ideario europeo que encarnó en el criollismo ilustrado ${ }^{16}$. Para la realización de este modelo era necesario "limpiar" lo que había en nosotros de indígena y de negro, papel en el que la escuela y la Iglesia ocuparon un lugar protagónico. Estas imágenes estuvieron cruzadas por la idea de un ciudadano virtuoso que respetase tanto las leyes civiles como las morales, de tal suerte que el buen ciudadano se homologó al ideal cristiano, legitimando de paso la injerencia de la Iglesia católica en la construcción de la identidad nacional y en el proyecto de Estadonación: "La Iglesia ha sido sin duda la verdadera creadora y modeladora del alma nacional" 17 .

En el contenido de los textos escolares, se evidencia a menudo la superposición entre el campo de lo político y lo religioso; allí podemos apreciar la iconografía nacionalista revestida de un hálito sagrado para legitimarse:

¡Patria! Por ti sacrificarse deben, bienes y fama y gloria y dicha y padre. Todo, aun los hijos, la mujer, la madre. Y cuanto Dios en su bondad nos dé. Todo, porque eres más que todo del señor Dios

15 Federico Climent Ferrer (1920). Educación cívica: principios fundamentales de los derechos y deberes de ciudadanía en la vida social. Madrid-Barcelona: Editorial Calpe, p. 24.

16 John Lynch (2001). Las revoluciones hispanoamericanas 1808-1826 trad. de Javier Alfaya y Barbara McShane, $8^{\mathrm{a}}$. ed., ampliada y puesta al día. Editorial Ariel.

17 J. Camilo. y B. Matos (1947). Resumen de la historia de Colombia. Texto para la enseñanza primaria. Bogotá: Librería Colombiana. p. 132. 
la herencia justa y rica. Hasta su honor el hombre sacrifica por la Patria y la Patria por la Fe18.

Puede decirse entonces que mediante el estudio de los textos escolares sobre ciencias sociales de la primera mitad del siglo XX, es posible auscultar los rasgos específicos de la cultura política del período, tales como los conflictos ideológicos, la influencia de la religión católica en la construcción del ideario de nación, los imaginarios regionales, la exclusión de los sectores populares, la intolerancia política y racial, entre otros. En síntesis, las particularidades que conforman nuestra modernidad política y los avatares de la construcción del EstadonNación durante los siglos XIX y XX.

\section{El vértigo de vivir entre siglos}

Transcurrido el siglo XX y situados en la primera década del XXI, resulta indudable que las preocupaciones de las que buena parte de mi generación es heredera, en torno a las identidades nacionales y su relación con los estados y a las maneras como éstas nos han conformado en cuanto sujetos políticos y sociales, precisan ser resignificadas en el sentido señalado por Hobsbawm, uno de los estudiosos de la categoría moderna de nación, quien dice lo siguiente al respecto a la historia del mundo de finales del siglo XX y comienzos del XXI:

Tendrá que escribirse inevitablemente como la historia de un mundo que ya no cabe dentro de los límites de las "naciones" y los "estadosnación" como solían definirse, ya fuera política, económica, cultural o incluso lingüísticamente. Será en gran parte supranacional e infranacional, pero incluso la infranacionalidad, se vista o no de mininacionalismo, reflejará el declive del antiguo Estadonación como entidad capaz de funcionar. Verá los "estadosnación" y las "naciones" o los grupos étnico/lingüísticos principalmente en relación con la nueva reestructuración supranacional del globo, retirándose ante su avance, resistiéndose o adaptándose a ella, viéndose absorbidos o dislocados por ella. Las naciones y el nacionalismo

18 Belisario Palacios (1896). Historia de Colombia para uso de las escuelas primarias, extractada de varios autores. Bogotá: Editorial M. Rivas, p. 4. estarán presentes en esta historia, pero interpretando papeles subordinados y a menudo bastante insignificantes. Esto no quiere decir que la historia y la cultura nacionales no ocupen un puesto importante-quizá más importante que antes-en los sistemas de educación y la vida cultural de determinados países, especialmente los más pequeños, ni que no puedan florecer localmente dentro de un marco supranacional mucho más amplio19.

Desde este nuevo contexto es necesario repensar el problema de la constitución de los estados nacionales en el siglo XXI y los procesos de formación y aprendizaje ciudadanos, así como sobre el papel de los textos escolares en ciencias sociales y las diferentes formas de constitución de subjetividades en las sociedades actuales.

Como un libro es un nudo en una red en la que están inmersos múltiples autores, donde se evidencia que pertenecemos a un mismo campo cultural en el que nuestras prácticas se interceptan e interpelan de manera continua, formando de modo condensado el bagaje intelectual de una época, acudo, ya para terminar al prólogo que escribió para nuestro libro el comunicólogo e historiador Fabio López de la Roche, respecto a la contemporaneidad del mismo. Sus palabras me permiten creer esperanzada, de la mano de Koselleck, que miro hacia el pasado con las expectativas del presente y los horizontes de espera que trazan el futuro de allí derivados. Esto me hace sentir que no estoy sola y que en mi transcurso como ser histórico se sitúan no sólo las generaciones que me precedieron sino también las que me suceden, entre quienes se cuenta mi sobrina nieta, mi ahijada, para pensar que este viaje hacia el pasado, que busca revivir nuestros muertos pero para darles una digna sepultura, como diría Ricoeur20, tiene algún valor social para todos nosotros. He aquí las palabras de Fabio:

Para las nuevas generaciones que han crecido en medio de otros dispositivos de creación y sociali-

19 Eric Hobsbawm (1991). Naciones y nacionalismo desde 1780. Barcelona: Grijalbo Mondadori, p. 201.

20 Paul Ricoeur (2004). La memoria, la historia, el olvido, Buenos Aires: Fondo de Cultura Económica. 
zación de referentes e imaginarios de nación -El Pibe Valderrama, la Selección Colombia, Aterciopelados, Shakira, Juan Pablo Montoya construidos simbólicamente desde dispositivos de cultura mediática, y cuando el sistema escolar, la familia tradicional y la religión católica ya no tienen el lugar hegemónico que ocupaban en aquellos días, este libro puede tener también una función importante y básica de memoria y de atención por estadios precedentes de nuestra configuración cultural, cuyo conocimiento permitiría una adecuada valoración de las transformaciones socioculturales vividas por la sociedad colombiana en la segunda mitad del siglo XX, las cuales hicieron de ella otra

\section{Bibliografía}

Anderson, Benedict (1983). Imagined communities: reflections on the origins and spread of nationalism. Londres: Verso.

Botero, José Manuel (1942). Geografía física y de la República de Colombia. Medellín: Tipografía Bedout.

Choppin, Alain (2002). História dos livros e das ediçoes didáticas: sobre o estado de arte, en: Paedagogica Histórica, Vol. 38, No 1, 2002.

Climent, Ferrer Federico (1920). Educación cívica: principios fundamentales de los derechos y deberes de ciudadanía en la vida social. Madrid - Barcelona: Ed. Calpe.

De Barros, Manoel (2003). Sobre sucatas, Poema XV, en: Memórias inventadas: a infancia. Sao Paulo: Planeta.

Duarte, Suárez E. (1942). Instrucción cívica. Bogotá: Editorial Iqueima.

Herrera, Martha Cecilia; Pinilla, Díaz Alexander y Suaza, Luz Marina (2003). La identidad nacional en los textos escolares de ciencias sociales: Colombia, 1900-1950. Bogotá: Ántropos.

Hobsbawn, Eric (1991). Naciones y nacionalismo desde 1780. Barcelona: Grijalbo Mondadori.

Inspección Nacional de Educación (1933). Programas de ensayo para las escuelas primarias. Bogotá: Imprenta Nacional.

Jiménez, Camilo y Matos, Belisario (1947). Resumen de la Historia de Colombia. Texto para la enseñanza primaria. Bogotá: Librería Colombiana. sociedad, comparativamente con la aquí presentada, pero en la cual aún es posible encontrar inercias, huellas y expresiones de esa compleja y abigarrada modernidad que nos tocó vivir21.

Mujer nacida en el siglo XX, habitante de Colombia, eso soy. Sí, ciudadana de nuestra Colombia en el siglo XX, sin duda. Marcada por imágenes religiosas, por luchas políticas, por utopías feministas, por imaginarios nacionales, que se asoma con asombro profundo al devenir del siglo XXI. Como diría Juan Rulfo en Luvina: "Usted ha de pensar que le estoy dando vueltas a una misma idea. Y así es, sí señor..."22.

Kosselleck, Reinhart (1993). Futuro pasado: para una semántica de los tiempos históricos. Barcelona: Paidós.

Lynch, John (2001). Las revoluciones hispanoamericanas, 1808 - 1826. Buenos Aires: Ariel.

Nora, Pierre (dir.) (2001). Les Linux de mémoire, Coll "Quarto". París: Gallimard.

Palacios, Belisario (1896). Historia de Colombia para uso de las escuelas primarias, extractada de varios autores. Bogotá: Ed. M. Rivas.

Posada, Roberto y Cortázar, Toledo Roberto (1912). Instrucción cívica. Bogotá: Ed. Casis.

Ricouer, Paul (2004). La memoria, la historia, el olvido. Buenos aires: Fondo de Cultura Económica.

Ríos, Juvenal (1943). Curso de antropogeografía colombiana. Bogotá: Tipografía Colón.

Rulfo, Juan. Luvina, en: http://www.ciudadseva.com/ textos/cuentos/esp/rulfo/luvina.htm

Sánchez, Santamaría Ignacio (1926). Cartilla Cívica: Catecismo del ciudadano para el uso de escuelas y colegios de Colombia. Bogotá: Sociedad Editorial.

Santos, Montañés José (1914). Curso de Geografía elemental para el moderno Sistema cíclico Inductivo: Primer ciclo escrito. Bogotá: Arboleda y Valencia.

21 Martha Cecilia Herrera, Alexis V. Pinilla Díaz y Luz Marina Suaza. Op cit., p. 16.

22 Juan Rulfo, Luvina, en www.ciudadseva.com/textos/cuentos/esp/ rulfo/luvina.htm. 